\section{Computer Aided Risk Simulator}

Helga Peter ${ }^{1}$ und Thomas Penzel ${ }^{2}$

${ }^{1}$ Marburg, Deutschland

${ }^{2}$ Interdisziplinäres Schlafmedizinisches Zentrum, Charité -

Universitätsmedizin Berlin, Berlin, Deutschland

\section{Definition}

Fahrsimulator.

Siehe $\triangleright$ „Leistungstests und Fahrtauglichkeitsprüfung“.

\title{
Synonyme
}

C.A.R. 